\title{
STRENGTH AND DURABILITY OF KENAF FIBER REINFORCED CONCRETE FOR MARINE STRUCTURES
}

\author{
NUR FIKRIAH HASHIM, NURAQILAH MOHD ZAINAL, NURAIN JAMIL, NURUL NASUHA MOHD \\ NOR AND SURIANI MAT JUSOH*
}

Programme of Maritime Technology, School of Ocean Engineering, Universiti Malaysia Terengganu, Kuala Nerus, Malaysia

*Corresponding author: surianimatjusoh@umt.edu.my

\begin{abstract}
Nowadays, Kenaf fiber is sustainably useful in marine structures and has become one of the materials that may be high in demand as it is light, biodegradable and environmental friendly. This study investigates the effect of fiber percentage on compressive strength of fiber reinforced concrete (FRC) and the relationship between compressive strength and time of FRC immersion in seawater. FRC concrete cubes were prepared using four different percentage of fiber $(0 \%, 1.5 \%$, $3.0 \%$ and $4.5 \%$ ). These FRC were immersed in seawater for 7, 14 and 21 days for three consecutive weeks. Based on the experiment, it was found that there was improvement in compressive strength of FRC when compared to plain cement concrete. The results showed that $3.0 \%$ of KF to cement matrix concrete determined the highest compressive strength of $205.43 \mathrm{~Pa}$ while $0 \%$ of KF fiber to cement concrete matrix (control specimen) showed the lowest compressive strength of $158.28 \mathrm{~Pa}$. Also the addition of Kenaf fiber to cement concrete decreased the seawater absorption more than concrete with absolutely $0 \%$ of KF fiber to cement concrete (control specimen). In conclusion, the results did show significant improvement and a consistent trend on strength with the addition of FRC. This study also revealed that the percentage of water absorption was on the increase for 0,7 and 14 days and become constant after day 21 . This is due to manufacturing defects that occurred which block the water from entering the material and making the material absorb less water.
\end{abstract}

Keywords: Compressive strength, Kenaf fiber, reinforced concrete, seawater, water absorption

\section{Introduction}

Generally marine structures play a major role in the building or production of maritime products that are used for industry. Marine structure construction has used many types of materials, moving from one material to another, for example, from wooden material to modern material including natural fibres that are considered as strong materials. As a result, marine structures have become more important than before due to high demand from the customers, and at the same time the construction has become one of the important industry that can generate income for the country.

One of the constituents of natural fibre reinforced plastic composites in Malaysia is Kenaf fibre. Research in Kenaf has been growing tremendously. Kenaf long fibre could be used for a wide variety of applications if the properties are found to be comparable to existing synthetic composites. Since Kenaf is always available in long fibre form, the mechanical properties found could be of use in many industrial applications such as insulator seals. In addition, Kenaf fibre offers the advantages of being biodegradable, low in density, nonabrasive during processing and environmentally safe (Nishino, 2003). Kenaf in comparison with other natural fibers is ecofriendly with high growth rate. So, in this current work, investigation was carried out to study the suitability of Kenaf reinforced concrete to be used in marine construction as new materials replacing current materials. The manufacturing defect and tensile properties of Kenaf reinforced concrete was observed. It was also important to investigate the water absorption of this natural fiber in order to draw a conclusion whether Kenaf is technically capable of replacing the current materials used for marine constructions.

This study is concerned with the percentage of seawater absorption and the compressive strength of concrete containing Kenaf fiber as reinforcement. Natural fibers are also used to replace asbestos fibers, which are expensive and dangerous to health. They are also mostly used in developing subtropical and tropical countries in Africa and South-East Asia as reinforcement for concrete elements for housing. The application of Kenaf and locally available fibers may help considerably 
in building low-cost houses (Krenchel \& Hejgaard, 1975). While the period immersed in seawater is the duration the concrete containing fibers were immersed in seawater, whether for 7,14 and 21 days. The

\section{Methodology \\ Materials}

\section{i) Kenaf Fiber}

The specimens of Kenaf fiber reinforced composites were prepared at various fiber ratios of $1.5 \%, 3.0 \%$ and $4.5 \%$. $0 \%$ of fiber ratio was used as control specimen. Kenaf fiber was cut into long fiber with sizes ranging between 10 to $12 \mathrm{~mm}$ long. The size was kept constant for every specimen.

\section{ii) Cement}

Ordinary Portland cement (ASTM Type 1) from single source was used throughout the study.

\section{iii) Aggregate}

There were two types of aggregates used, which were sand as fine aggregates, and granite and crushed rock as coarse aggregates. performance of fiber reinforced concrete also depends on the matrix mix ingredients. The matrix strength of fiber reinforced concrete has significant influence on the toughness characteristics (Razak, 2011).

\section{iv) Water}

Water was the key ingredient in this fiber reinforced concrete fabrication. It acted as a hardener of concrete through a process called hydration.

\section{Specimen preparation and test procedures}

The mix proportion of the experiment, as given in Table 1 below, used concrete mix ratio of 1:1.5:3 using concrete mix design of M20 grade of concrete following the procedure as done by Sinha (2002). Mixing was done manually on a clean container and the materials were thoroughly mixed in the dry state, after which water was added gradually while thoroughly mixing the concrete. Lastly, the fibers were added and mixed until the concrete mixture became uniform in colour and consistency. There were a total 12 concrete cubes made according to fiber percentage $(0 \%, 1.5 \%, 3.0 \%$ and $4.5 \%$ ) and for every 7, 14 and 24 days. They were then demolded and left to dry under the sun for 2 days (about $30^{\circ} \mathrm{C}$ temperature).

Table 1: Mix propotion

\begin{tabular}{lll}
\hline No & Materials & Amount (\%) \\
\hline 1. & Cement & 17 \\
2. & Coarse Aggregate (granite) & 50 \\
& & \\
3. & Fine Aggregate (sand) & 25 \\
4. & Kenaf Fiber & i. 1.5 \\
& & ii. 3.0 \\
& & iii. 4.5 \\
5. & Water & 8 \\
\hline
\end{tabular}

After 2 days, the concrete cubes were ready to be cured in seawater with salinity around 30-35 g/kg following the procedure done by Abdullah (2017).

The percentage of water absorption was determined using Equation 1 below:

Water absorption $(\%)=\frac{W_{1}-W_{0}}{W_{0}} X 100$

(Equation. 1)

Whereby:

$W_{1}$ : weight after immersion

$W_{2}$ : weight at initial

The concrete cubes were cured in seawater for 7, 14 and 21 days and compressive strength was tested. Compression tests were conducted using Geotech Universal Testing Machine and the compressive strength of the concrete cube was determined using Equation. 2:

$$
\begin{gathered}
\text { Compressive Strength }\left(\frac{N}{\mathrm{~mm}^{2}}\right) \\
=\frac{\text { Max load }(\mathrm{kN})}{\text { Area }\left(\mathrm{mm}^{2}\right)} \\
\text { (Equation. 2) }
\end{gathered}
$$


In this study, to validate the results of the compression tests, Scanning electron microscopy (SEM) was used to determine the surface morphology of the concrete cubes

\section{Results and Discussion Water Absorption}

The durability of Kenaf fibre reinforced concrete was tested using water absorption experiment. Based on Figure 2, plain concrete (control) had less percentage of water absorption than Kenaf fibre reinforced concrete after immersion in seawater for 7, 14 and 21 days. Based on Table 2, for the first two weeks, plain concrete had the highest water absorption that was $3.1 \%$ compared to the concrete cubes reinforced with $\mathrm{KF}$ which were $1.7 \%$, $0.06 \%$ and $1.8 \%$ respectively. It can claimed that with the presence of KF in the concrete, the lowest rate of after the compression test. The relationship between the compression test and surface morphology was analysed and discussed.

absorption was on day 21 that was $1.2 \%$. In some literature review, it has been said that the permeability of specimen increases with the fiber contents in all types of exposure environments (Ramli.et.al. 2008).

However we can see that KF reinforced concrete had the lowest percentage of water absorption at the end of the week. It is proven that KF has good water absorption properties in sea water. The Kenaf properties are lightweight, high strength, stiffness and biodegradability (Zakikhani et al., 2014). The percentage of water absorption became constant after 21 days of immersion.

Table 2: Water absortion

\begin{tabular}{llll}
\hline $\begin{array}{l}\text { Water } \\
\text { Adsorption, } \\
(\%)\end{array}$ & $\mathbf{7}$ days & $\mathbf{1 4}$ days & $\mathbf{2 1}$ days \\
& & & \\
\hline $\mathbf{0 \%}$ & 2.4 & 5.6 & 6.0 \\
\hline $\mathbf{1 . 5 \%}$ & 5.8 & 7.5 & 7.1 \\
\hline $\mathbf{3 . 0 \%}$ & 6.4 & 6.4 & 6.1 \\
\hline $\mathbf{4 . 5 \%}$ & 4.6 & 6.4 & 1.2 \\
\hline
\end{tabular}

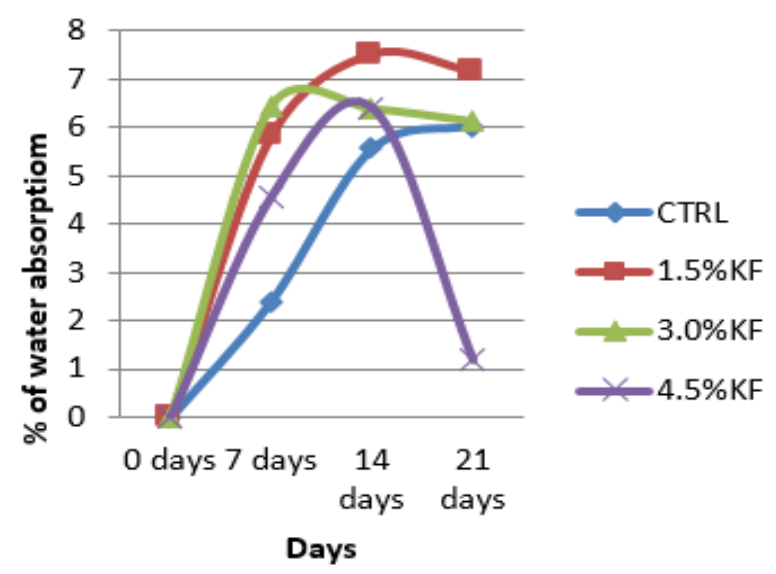

Figure 2: Water Absorption at different fiber percentages.

Compressive strength

Table 3 shows the result of compressive strength of KF reinforced concrete based on fiber percentages at interval week. 
Table 3: Compressive Strength of Kenaf fiber Reinforced Concrete

\begin{tabular}{llll}
\hline $\begin{array}{l}\text { Compressive } \\
\text { Strength, } \\
\left(\mathbf{N} / \mathbf{m}^{2}\right)\end{array}$ & Week 1 & Week 2 & Week 3 \\
\hline $\mathbf{0 \%}$ & 152.4 & 117.9 & 166.4 \\
\hline $\mathbf{1 . 5 \%}$ & 738.1 & 182.3 & 158.3 \\
\hline $\mathbf{3 . 0 \%}$ & 126.7 & 149.8 & 205.4 \\
\hline $\mathbf{4 . 5 \%}$ & 119.5 & 160.3 & 145.1 \\
\hline
\end{tabular}

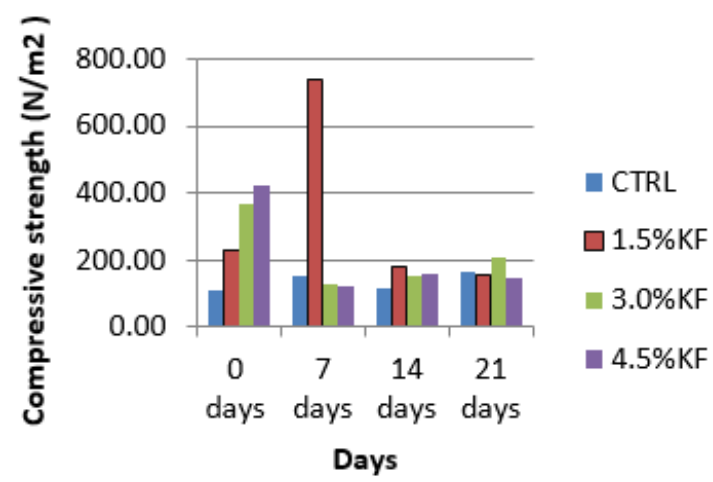

Figure 3: Compressive strength against immersion period (days).

Figure 3 shows that the plain concrete as control specimen had the lowest strength than KF series. But at day $21,3.0 \%$ of KF achieved its maximum strength. For $1.5 \% \mathrm{KF}$, the strength increased then decreased because it already achieved optimum level. At day 21, it shows that the $3.0 \%$ of fiber incorporated into the concrete increased the strength of Kenaf fiber reinforced concrete. The addition of Kenaf fibre resulted in concrete's increased toughness as compared with the plain concrete (Razak \& Ferdiansyah, 2008). Performance of fiber reinforced concrete may decrease due to weak interfacial adhesion between fiber and matrix. This is because interfacial bonding adhesion leads to important composite properties such as composite strength, fracture energy, ductility and energy absorption capacities (Li et.al., 1994).

\section{SEM Surface Morphology}

For further understanding of the damage modes of composite materials, we can analyse the factors that influence the failure. In composite materials, failure may be caused by fiber breakage, composite cracking, or fiber/composites de-bonding (Chamis, 1989). In this study, it was found that the types of failure such as fiber breakage, fiber pull-out and fiber irritation could be determined by using SEM. Figure 4 depicts SEM micrograph of fiber pull-out in the specimen of $3.0 \% \mathrm{KF}$.

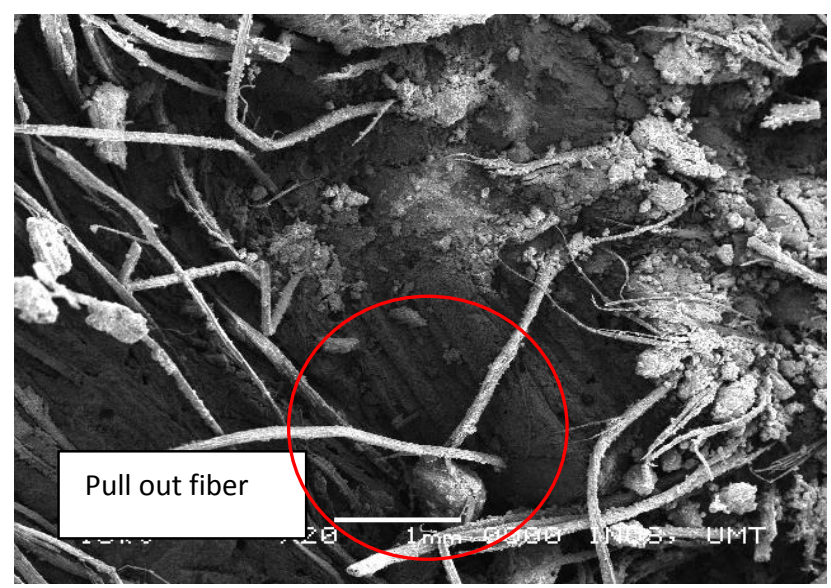

Figure 4: SEM micrograph of cement matrix reinforced with KF. 
Figure 4 depicts the poor interfacial adhesion that caused fiber pull-out between fiber and concrete which could disturb composite's performance. Excessive voids due to poor mixing and poor interfacial bond adhesion between fiber and concrete are common factors that affect the performance of the materials as claimed by Joneja and Nevaz (1984). This image supports the failure of composite bonding as mentioned in the SEM micrograph whereby the fibers tended to pull-out which may be due to possible frictional contact between fibers and the concretes.

\section{Conclusion}

This study investigated the strength and durability of KF reinforced concrete for marine construction using selected specimens representing the natural fibre reinforced composite material. There were three different percentage of KF used to reinforce the concrete. This method enabled other tests such as compressive test and water absorption test to achieve the objectives stated.

KF reinforced concrete did show better performance than concrete without KF in seawater absorption test. The increase in fiber percentage helped to close the void on the concrete surface to become impermeable to seawater. In general the compressive strength of KF reinforced concrete did show an increment compared to plain concrete. The incorporation of KF into the mix had a positive effect on the ductility and increased toughness characteristic but depending on the environment. Scanning electron micrographs indicated good bond between the KF and the surrounding matrix and provided some hints regarding the possible failure mode and damage progression of the KF reinforced concrete which could facilitate future modelling efforts. The research findings of this study indicate that KF is a sustainable material, light and water resistant.

\section{Recommendations}

This study recommends that suitable water cement ratio be used when dealing with the mix proportion of concrete to produce good concrete without defects that can cause failure. Then, the size of coarse aggregates plays an important role in reducing surface voids. Also, during the manufacturing process of Kenaf fiber reinforced concrete, hammering technique needs to be applied when casting in the mold,. This measure is to reduce the defects during manufacturing process such as surface void and misaligned fibers. Quality control is needed when dealing with all the specimens to identify the best percentage of fiber to be incorporated into the concrete.

\section{Acknowledgements}

I would like to thank all the staff and technicians at Maritime Technology Laboratory, School of Ocean Engineering, Universiti Malaysia Terengganu (UMT) for their support during the completion of this final year project.

\section{References}

"Standard Test Method for Tension-Tension Fatigue of Polymer Matrix Composite Materials," in Annual Book of ASTM Standards, ed, 2012.

A. N. Towo and M. P. Ansell (2008). Fatigue evaluation and dynamic mechanical thermal analysis of sisal fibrethermosetting resin composites. Composites Science and Technology, vol. 68, pp. 925-932.

ACI Committee 544, Measurement of Properties of Fiber Reinforced Concrete, (ACI 544.2R-78), American Concrete Institute, Detroit, 7 p. (1978).

ACI Committee 544, Measurement of Properties of Fiber Reinforced Concrete, (ACI 544.2R-78), American Concrete Institute, Detroit, 7 p. (1978)

Bergströn, Sven G., Hans-Erik Gram. (1984). Durability of alkali-sensitive fibres in concrete. The International Journal of Composites and Lightweight Concrete, London, v. 6, n. 2, May, p. 75-80. 1984.

Brandt, A. (1995). Reinforcement of cement-based composites. In Cement-based composites: Materials, mechanical properties and performance. London: E \& FN Spon.

Canovas, M. F.; Selva, N.H.; Kawiche, G.M. (1992). New economical solutions for improvement or durability of Portland mortars reinforced with sisal fibres. Materials and Structures, Paris, v. 25, p. 417-422.

Craig, R.J. (1984). Structural Applications of Reinforced Fibrous Concrete, ACI Concrete International, 6(12): 28-323.

Kannan Rassiah and M.M.Megat Ahmad (2012). A review on Mechanical Properties of Bamboo Fiber Reinforced Composite, Australian Journal of Basic and Applied Sciences, pg247-253

Maurizio Avella, Review of Eco-Challenges of Bio-Based Polymer Composites, ISSN Materials journals, 2009, pg911-925

Meyyappan, P., Sivapragasam, C., Sekar, T., \& Marimuthu, K. (n.d.). Suitability of Composite Material in Tsunami Resistant Design. Aquatic Procedia, 397403.

Naaman, A.E. (1985). Fiber Reinforcement for Concrete, ACI Concrete International, 7(3): 21-25. 
Naaman, A.E., Fiber Reinforcement for Concrete, ACI Concrete International, 7(3): 21-25 (March, 1985).

Nishino T., Hirao K., Kotera M., Nakamae K. and Inagaki H. (2003). Kenaf reinforced biodegradable composite. Compos Sci Technol, Vol. 63, pp. 1281- 86.

Papathanasiou,, T., \& Guell, D. (1997). Flow induced alignment in composite material. Abington hall, Abington: Woodhead publishing.

Ramualdi, J.P. and Batson, G.B. (1983). The Mechanics of Crack Arrest in Concrete, Journal of the Engineering Mechanics Division, ASCE, 89:147-168.
Ramualdi, J.P. and Batson, G.B. (1983). The Mechanics of Crack Arrest in Concrete, Journal of the Engineering Mechanics Division, ASCE, 89:147-168.

S. Shah, A. Patil, Ramachandran. M, K. Kalita. (2007). "Effect of coal ash as a filler on mechanical properties of glass fiber reinforced material." Int. J. of Applied Engineering Research (IJAER), Volume 9, Issue 22.

Schutter, G., \&Audenaert, K. (2004).Evaluation of water absorption of concrete as a measure for resistance against carbonation and chloride migration.Materials and Structures, 37, 591-596. 